\title{
O BANCO MUNDIAL E O COMBATE À POBREZA NO NORDESTE: o caso da Paraíba
}

\author{
FlákioLúnoRodiguss Viẹa*
}

\section{INTRODUÇÃO}

O artigo anal isa como, a partir do financiamento deprojetos de desenvol vimento, as agências internacionais interferem não apenas nas proposições, masna execução, nos objetivos ena própria lógi ca desses projetos. No caso em tela, analisaremos o Projeto Cooperar (Projeto deCombateà Pobreza Rural do Estado da Paraíba), que conta comfinanciamento do Banco Mundial.

O Projeto Cooperar épartedeum programa mais amplo do Banco Mundial, decombater à pobreza rural no Nordeste, o Northeast Rural Poverty Alleviation Program - Programa deAlívio daPobreza Rural no Nordeste-, eestá plenamentearticulado às novas estratégias dessainstituição, delineadas a partir do objetivo decombater a pobreza através do estímulo à participação das populações locais na definição dos investimentos do Estado. ${ }^{1}$

* Doutor em Sociologia, pela UFPE. Professor do Departamento de História e da Pós-Graduação em História e Serviço Social da UniversidadeFederal da Paraíba - UFPB. Rua João Cabral de Lucena, n.ํ20/503 - Bessa - João Pessoa.PB Cep:58035-105. flavioluciov@uol.com.br

${ }^{1}$ O Projeto Cooperar tem seus similares no Nordeste. $\mathrm{Na}$ Bahia, é denominado Produzir, no Ceará, São José, em Pernambuco, Prorural, no Maranhão, Prodim, em Sergipe, Santa Maria; nos outros estados do Nordeste, el e é designado como Projeto de Combate à Pobreza Rural .
Nossa análise tem por base documentos produzidos pelo Banco Mundial e pelo órgão do Governo da Paraíba responsável pela execução do Projeto Cooperar. Acreditamos que seu exame permi te constatar uma ampliação das limitações não apenas do Estado nacional brasileiro, mas também das esferas de poder subnacionais, de elaborar projetos dedesenvol vimento fundadosem estratégias nacionais e (ou) regionais. Essas estratégias foram abandonadas por orientações pautadas pelos localismos e, portanto, fragmentárias, que se originam por dentro de instituições externas, a exemplo do Banco Mundial, cuja explicitação é apresentada em projetos como o que aqui vamos anal isar.

Essas proposições estão em estrita consonância com o novo paradigma de desenvolvimento sustentável, introduzido no Nordeste desde 1994, depois da conclusão do Projeto Áridas (Brasil, 1994), e reafirmadas, a partir de 1995, com a el aboração, deplanos de desenvol vimento sustentável pelosgovernos estaduais dessa Região (Vieira, 2004). Não cabeaqui discutir esse processo, ape nas indicar que as propostas esboçadas são declaradamentedefendidas peloBanco Mundial e 
seinserem no amplo quadro dereestruturação do Estado que ocorre desde então, no Brasil e no Nordeste.

Tais características serevelam, em primeiro lugar, no que se refere ao problema do combateà pobreza. No Relatório sobre o Desenvolvimento Mundial, de1990 (Banco Mundial, 1990), queteve a pobreza como tema central, foram esboçadas estratégias para combatêla, tendo como objetivo principal declarado a criação deoportunidades econômicas para a geração derenda. Para o Banco Mundial , éisso quejustifica a proposta de desenvolvimento sustentável, como foi explicitado, doisanos depois, no relatório sobre desenvolvimento mundial, de 1992, cuja temática focal izava as relações entre desenvolvimento e meio ambiente (Banco Mundial, 1992, p.1). Nessedocumento, foram retomados os argumentos acerca do crescimento populacional, abordagem habitual nos anos 1970, especialmenteapós a publicação do célebrerelatório do ClubedeRoma, intitulado Limites do crescimento (Meadows et al., 1978), com seus impactos sobreo desenvol vimento econômico agorajáajustados ànova conjuntura dehegemonia neoliberal .

Nos anos 1990, as análises foram redirecionadas paraumoutrolimitedo crescimento econômico, a pobreza, segundo o Banco Mundial, aprincipal geradora da degradação ambiental (Banco Mundial, 1992, p.28-31). Dessa forma, épossível inferir que, para o Banco Mundial, a pobreza seconfigura como a variável principal queexplica o crescimento dos problemas ambientais, o que nos permite concluir sobre quem são os grandes responsáveis pelos problemas ecológicos atuais. Por isso, para o Banco Mundial, "o alívio da pobreza é tanto um imperativo moral como um re quisito prévio indispensável para chegar a sustentabilidadeambiental. Os pobres são ao mesmo tempo vítima eagente da degradação do meio ambiente" (1992, p.32). Ao mesmo tempo, afirma que "há uma sinergia considerável entre o al ívio da pobrezaea proteção do meio ambiente." (p.34). Assim, o desenvolvimento sustentável deve compatibilizar crescimento econômico, combateà pobreza epreservação ambiental , ea estratégia pro- postaédirigida especificamentepara os países “em desenvolvimento" (Banco Mundial, 1992).

Nos relatórios de 1990 e 1992, conjugaramse dois pontos centrais que constitui rão o fundamento da estratégia de desenvol vimento proposta pel o Banco Mundial para os países "em desenvolvimento" eque determinarão a lógi ca dos programas financiados pel o BIRD a partir da década de 1990: combateà pobreza edesenvolvimento local. Assim, a relação entresustentabilidadeambiental e desenvol vimento só pode se real izar pel o combateà pobreza. Ressal te-setambém que o elemento central da estratégia de desenvol vimento sustentável éa participação das comunidades locais:

Os enfoques baseados na participação têm três vantagens principais: a) permitem aos planejadores compreender mel hor os val ores, os conhecimentos ea experiência da população local; b) ajudam a ganhar o respal do da comuni dade quanto aos objetivos dos projetos ea assistência comunitária para a execução ao nível local, e c) podem ajudar a resolver os confl itos com respeito ao uso dos recursos (Ibid., 99).

Não éàtoa, portanto, quecombateà pobrezaedesenvolvimentolocal aparecem comoverda deiras panacéias nas discussões enos projetos de desenvol vimento desde então, sendo que ambos os termos são partes essenciais do conceito de desenvolvimento sustentável. No entanto, a transição para a hegemonia dessas idéias e práticas durou pel o menos duas décadas atéqueelas aparecessem na forma como seapresentam hoje.

Tendo em vista tais mudanças, consideramos fundamental recuperar o modo como as políticas para o Nordesteevoluíram dos anos 1970 aos 1990, sem deixar delevar em conta as transforma çõesocorridas no Estado ena economia brasileira. Assim, acreditamos queficará mais claro o sentido das mudanças ocorridas e o estado em que se encontram as políticas de desenvolvimento no Nordeste, hojecentradas no combateà pobreza e no desenvolvimento local. 
DO POLONORDESTE AO PROJETO ÁRIDAS: dos pólos de desenvolvimento ao desenvolvimento local

A Sudene, criada em 1959, foi a instituição que ajudou a consol idar o processo de integração do Nordeste ao mercado nacional e coordenou as ações do Estado brasileiro na região, sendo, portanto, o principal instrumento da modernização econômica esocial do Nordeste. A sua constituição é resul tado das preocupações desenvolvimentistas predominantes à época, e, sem dúvida, éa expressão mais bem acabada de um pensamento que se tornou ação, nascido sob a influência do desenvolvimentismo brasileiro e, em grandemedida, da obra de Celso Furtado.

No início dos anos 1970, uma nova estraté gia de desenvol vimento foi elaborada, eo papel da Sudene foi redefinido, com a perda de sua autonomia relativa para formular as políticas dedesenvolvimento regional. Quando foi criada, aSudene era vinculada diretamenteà Presidência da República. A partir de 1972, a estratégia de desenvolvimento regional brasileiro passou a ficar atreladaà estratégia dos Planos Nacionais de Desenvol vimento (PND). Desdeentão, tais definições foram concentradas no Ministério do Planejamento. A nova estratégia tinha por base a criação de condições para a intensificação do processo de integração inter-regional, através do Plano de Integração Nacional (PIN), queconcentrou suas ações na construção de rodovias, como foi o caso da Transamazônica, além do Programa de Redistribuição de Terras e de Estímulo à Agropecuária do Norte-Nordeste(Proterra). O objetivo dessePrograma era favorecer o deslocamento dos "excedentes" populacionais, especial mente nordestinos, para a nova frontei ra agrícola local izadanoNorteeno Centro-Oeste, procurando, com isso, diminuir as pressões decorrentes da grande concentração deterras na região, para preservar a secular estrutura fundiária do Nordeste.

Essas redefinições começaram a seconformar no I PND (1972-1974), que representou uma mudança na concepção do papel da agriculturano desenvolvimento econômico do país, com reflexos diretos sobre a questão agrária, por dois aspectos. O primeiro, éo abandono de uma concepção quetinha na resolução do probl ema agrário a via para a modernização das estruturas sociais do Nordeste(edo Brasil); eo segundo, a substituição da estratégia de desenvolvimento regional gl obal por uma estratégia de pól os de desenvolvimento. Para Gonçal ves Neto (1997), a estrutura fundiária, pela primeira vez, deixa deser apresentada como um dos gargal os do processo de desenvolvimento nacional , abolindo-sea reforma agrária como elemento estratégico das políticas de desenvolvimento. Com o Proterra, por exemplo, pretendeu-se viabilizar a agricultura nordestina, estimulandoa racional ização da sua estrutura agrária com a introdução de novas tecnologias, com ênfase na a irrigação.

Em 1974, o Governo Federal Iançou o Programa deDesenvol vimento deÁreas Integradas do Nordeste(Polonordeste), eo ProgramaEspecial de A poio ao Desenvolvimento da Região Semi-árida do Nordeste, o Projeto Sertanejo. Esse Projeto era dirigido no sentido deestimular o desenvolvimento das áreas secas do Nordeste. Quanto ao Polonordeste, antes dequal quer coisa, érelevante reconhecer queesseprojeto éa expressão mais bem acabada danova estratégia de desenvol vimento re gional , pois sevolta para a concentração dos investimentos em determinados espaços considerados estratégicos (Valle, 1977), expressando, como seu próprio nomeindica, uma estratégia de criação de "pólos dedesenvolvimento" regional mentearticulados. Por outro lado, ele representa uma inflexão decisivadaestratégiadedesenvolvimento rural, cujo delineador maisimportanteéo Estado.

Essa abordagem tem um lastro teórico. A teoria dos pól os de desenvolvimento foi originalmente el aborada por François Perroux, nos anos 1950, no cal oroso debatesobre desenvolvimento econômico esocial, que perpassou aquela década e as duas seguintes. Em um sentido mais amplo, segundo essa teoria, a economia capital ista tenderia a produzir pólos que se constitui riam a partir dalocalização deindústrias num determinado es- 
paço econômico, as quais desempenhariam uma força centrípeta na atração denovos investimentos (Perroux, 1974). Esses pól os estabel eceriam relações com outros espaços polarizados através da estruturação desistemas detransportes ecomunicações, estruturando eixos de desenvolvimento. Procurava-se, com os investimentos nas áreas delimitadas, produzir efeitos irradiadores na economiaregional.

É convenientelembrar aqui a reverberação dessas formulações no âmbito do planejamento regional na década de 1990, especialmente nas primeiras elaborações do governo de Fernando HenriqueCardoso sobreum projeto de desenvolvimento sustentável para o Nordeste, aspectos que anal isamosemoutro lugar (Vieira, 1997). Umaoutra permanência quesemostra presentenas el aborações sobre desenvolvimento sustentável diz respeito à diferenciação que Perroux faz entre crescimento edesenvolvimento. Para Perroux, o fundamento do desenvolvimento "é a combinação de mudanças sociaisementais deumapopulação que a tornam apta a fazer crescer, cumul ativamentee de maneira durável [diz-se hoje sustentável] seu produto real, global" (Perroux, apud Andrade, 1973, p.55). Ou seja, o desenvolvimento exprime umavanço quetranscendeos dados material mente verificáveis, econômicos, expressando mudanças culturais, sem as quais sua reprodução se torna inviável. O desenvol vimento tem umimpacto mais homogêneo na sociedade, ao passo que "o crescimento não surgeem todaa parteao mesmo tempo; manifesta-secom intensidades variáveis, em pontos ou pólos decrescimento; propaga-se, segundo vias diferentesecom efeitosfinais variáveis, noconjunto daeconomia." (Perroux, 1967, p.164).

Rigorosamente, estánessaação planejadao resultado mais visível da economia nordestina contemporânea. ${ }^{2}$ Os pólos de desenvolvimento lograramal cançar expressivos níveisdecrescimento deprodutividadeeincremento tecnológico, mas os efei tos propagadores esperados para o restante

2 Para uma análise gl obal dos resultados das ações do Estado brasileiro no desenvolvimento econômico e social do Nordeste desde a criação da Sudene, ver Araújo (1995). da economia regional - objetivo do Pol onordeste (Valle, 1977, p.20) - pouco se fizeram sentir. Ao contrário, as desigualdades espaciais foram mantidas e, em muitos casos, até aprofundadas, quando não recriadas, e agravou-se a concentração derenda. Um caso paradigmático éo dos programas de colonização criados pela Codevasf, no Vale do São Francisco, que acabou por colocar o controle das terras destinadas à fruticultura nas mãos degrandes empresas e defamílias tradicionais, principais beneficiárias dos programas deirrigação (DaSilva, 1989).

O Polonordestefuncionava daseguintemaneira: os técnicos do projeto dividiama região em áreas geográficas, que recebiamações planejadas setorialmente (estradas, educação, saúde, saneamento, assistência técnica, comercialização), tendo em vistaas deficiências para o crescimento. No trecho citado a seguir, Antônio Rocha Magal hães (2000) - técnico do Ministério do Planejamento nos anos 1970, Secretário de Planejamento do Governo do Ceará (1987-1990), coordenador do Projeto Áridas (1993-1995) eassessor principal do Banco Mundial para o Brasil desde 1996- analisa as limitações da estratégia do Polonordeste.

A estratégia DRI [Desenvolvimento Rural Integrado] tinha lógica, mas dependia de um arcabouço institucional avançado, o que não se encontra em áreas atrasadas. Aí havia uma contradição em termos. Como cada ação deveria ser executada pela instituição setorial respectiva por exemplo, a assistência técnica pela Agência Governamental de Assistência Técnica (na época, a Embrater, no âmbito federal , ea Emater, no estadual) - acabava-se com uma impossibilidadedecoordenação deum grandenúmero deagências. Quando recebia os recursos, a Emater preferia utilizá-los nas suas próprias prioridades setoriais. E quando os utilizava na mesma região, o faziam num tempo diferente do das demais agências. Quando o projeto dava certo, a Emater tinha o mérito. Quando não dava, era o PDRI. Além do mais, a mai or parte dos recursos era utilizada na burocracia das agências executoras. Cerca da metade, apenas, era aplicada em ações finais e, como visto acima, não havia a integração desejada pelos planejadores. O arcabouço institucional era complicadíssimo. Além dasinúmeras agências estaduais, havia a coordenação regional na Sudene, a coordenação nacional no Ministério do Interior, a supervisão no Ministério do Planejamento e no I pea (Magal hães, 2000, p.2-3). 
A análiseacimaindica queo principal problema dos planos de desenvol vimento integrado eraacentral ização da burocracia estatal no controledas definições deinvestimentos eli beração de recursos. Essa crítica à burocratização do Estado evoluirá, nos anos 1990, como veremos, parauma pregação contra a presença regul adora do Estado, elemento justificador das políticas de desenvolvimento local. Numa análise retrospectiva e tendo em vista as preocupações atuais do Banco Mundial, torna-se rel evantetambém ressal tar, na análise acima, a estratégia de racionalização do uso dos recursos, que justifica tanto a neutralização do Estado no controle das políticas de desenvolvimento - o queéconsi derado fator de desperdício -, bem como a redução do seu papel, até então intransferível, de organizar o espaço nacional e regional. Esse dois aspectos, juntos, ajudam ale gitimar umaideologiaquevalidaumcomportamento político aparentemente despolitizado dos dirigentes estatais, que não têm mai s função decriação e elaboração estratégi ca, a não ser a reprodução deum model o cujas diretrizes já estão previamentedelineadas.

Não era esse o caso nos anos de 1970, já queos governos militares ai nda control avam com certa rigi dez aação do Estado no desenvol vimento econômico. ${ }^{3}$ Mas, é possível dizer que o Polonordeste representa um embrião das futuras políticas do Banco Mundial. Na segunda metade da década de 1970, o Banco Mundial inicia sua atuação no financiamento de projetos de desenvolvimento rural, vinculado ao Polonordeste. Em 1978, por exemplo, o Estado de Paraíba obtevefinanciamento para o Projeto de Desenvolvimento Rural Integrado do Brejo Parai bano (Wol rd Bank,

3 Para corroborar tal afirmação, é suficiente observar as linhas de financiamento do Banco Mundial na década de 1970. Nota-se que as políticas do Banco atendiam à exigência de rel ativa autonomia do Estado brasilei ro nas definições de suas próprias políticas, centradas ainda em uma estratégia de desenvol vimento industrial. Nos anos 1970, por exemplo, o Banco Mundial chegou a financiar um Projeto de Crédito Industrial do Nordeste no valor de US\$ 25 milhões (Esplar, 2004). Linhas de crédito desse tipo são inexistentes atual mente, porque políticas de incentivo à industrialização não são apenas desestimuladas; el as são total mente descartadas, restando apenas a chamada guerra fiscal entre os estados, principalmente os nordestinos.
1987). A participação do Banco Mundial no financiamento de projetos vol tados para o desenvolvimento rural, no fim da década de 1970 e meados da década de 1980, foi fundamental para aperfeiçoar os mecanismos de atuação do Banco no Brasil. Essa estratégia, centrada no desenvol vimento rural, queposteriormente "evoluiu para o combateà pobreza" (Magal hães, 2000), seráfundamental para consolidar a forma de atuação do BIRD nos anos 1990.

A experiência que o Banco Mundial acumulou desdeentão resultaránuma nova estratégia de desenvol vimento para o Nordeste, quecombina estratégias cada vez mais "gl obais", isto é, adaptadas às estratégias dos países desenvol vidos. Se gundo Chesnais, essa mudança podeser explicada quando, a partir dos anos 1980, o investimento externo direto foi drasticamente reduzido para muitos países periféricos, o que fez com que as políticas de combateà pobreza passassem a ocupar um lugar cadavez mais central nas estratégias dedesenvolvimento para instituições como o Banco Mundial. Ao mesmo tempo em queo combateà pobreza ganhava centralidade, "o tema do desenvolvimento foi colocado em surdina" (Chesnais, 1996, p.313). Ou seja, a crise da década de 1980, ocasi onada, em grande medida, devido aos crescentes impactos do endividamento externo, cujos reflexos desagregadores sobre o Estado desenvolvimentistano Brasil foram ressal tadospor vários autores, entreos quais citamos Fiori (1994), constitui um campo aberto para a implementação denovos modelos deascendência neoliberal. Se gundo o próprio Banco, o enfoquemudou nasúltimas décadas, deslocando-sedos projetos deinfra estrutura "para um paradigma mais abrangentede desenvol vimento, contando coma col aboração dos governos federal , estadual emunicipal", associado também ao significativo apoio dado a projetos de "reformas políticas e institucionais", ou seja, dereforma do Estado. No plano da ação econômica, o "enfoquerecentetem si do nas reformas dos setores fiscal, financeiro, el étrico, ambiental ede desenvolvimento humano" (Banco Mundial, 2004, p.1-3). É relevanteobservar, ainda, a crescentepar- 
ticipação das agências externas no financiamento de políticas públicas. No caso do BIRD, a participação dessa instituição já representa $12 \%$ de todos os investimentos públicos no Brasil. "Os empréstimosdoBanco Mundial, quecompõemuma grandeparcelado investimento público brasileiro, estão al tamenteconcentrados na redução da pobre za e no financiamento de programas destinados à região Nordeste" (2000, p.4). Com um volumetão expressivo de empréstimos, e não sendo o BIRD uma entidadedepropósitos humanitários, os “cuidados" em preservar a capacidadedo país decontinuar a pagá-los, para continuar a recebêlos, são incluídos entreas ações deapoio do Banco, especialmenteemmomentos decrisefinanceira:

Desde a eclosão da crise em di versas economias de mercado emergentes, em meados de 1997, o Banco Mundial vem identificando outras áreas nas quais o seu apoi o pode ser mais útil ao Brasil. Como parte desse esforço, preparou análises e recomendações sobre ajuste fiscal através de reformas estruturais e apoiou as autoridades federais para garantir que a austeridade fiscal e o desaquecimento econômico não tivessem um impacto desproporcional nas populações mais vulneráveis. (2004, p.3-4, grifos nossos)

Como jásalientamos, a conjuntura da década de 1980 foi marcada pela crise da dívida epelo conseqüente esgotamento do chamado Estado desenvolvimentistano Brasil. Essefato éessencial para seentender o aumento da ingerência dos organismosfinanceiros multilaterais nas estratégias dedesenvolvimento nacional. É significativotambémlembrar queos anos do governo do presidente José Sarney são de transição e marcados por fortecriseeconômica edescontroleinflacionário. Os financiamentos de organismos como o Banco Mundial, devido a limitações financeiras causadas pelo comprometimento fiscal como pagamento dos serviços da dívida, acabaram constituindo uma necessidade para a preservação do modelo queestava sendo gestado. A presença das agências definanciamento externo (BIRD eBID) nas políticas de desenvolvimento no Nordeste, desde então, se tornará cada vez mais visível, especialmente a partir do início da década de 1990, momento decisivo dereorientação eadesão do Esta- do brasileiro às políticas de liberal ização econômicaedereforma.

Dados sobreempréstimos do BIRD edo BID para financiamento de projetos desenvol vidos no Nordeste podem evidenciar o que foi dito acima. Na década de 1970, por exemplo, o val or dos empréstimos dos dois bancos para o Nordestenão alcançou os US\$ 330 milhões. Esses valores quase quadruplicaram na década de 1980, indo a pouco mais de US $\$ 1,3$ bilhão, ea mais de 1,6 bilhão na décadaseguinte. A té2004, esses val ores jáal cançavam os US\$ 648 mil hões (Esplar, 2004). Ou seja, de um total deUS\$2,36 bilhões em empréstimos liberados entre 1970 e 2004, apenas 13,9\% (US\$ 329 milhões) foramliberados na década de 1970.

A nova estratégia do Banco Mundial acompanha as redefinições que ocorreram nos organismos internacionais na década de 1980, como já tivemos a oportuni dade de demonstrar em outro trabal ho (Vieira, 2004), no transcurso dos debates sobrea nova estratégia de desenvolvimento para os países "em desenvolvimento", que viria a ser conhecida como desenvolvimento sustentável. Ao Iongo dos anos 1980, acontecimentos importantes no âmbito da redefinição das estratégias mundiais dos organismos internacionais terão impactos sobreas defini ções das políticas de desenvol vimento no Brasil, enquanto, como vimos, aumentava a participação das agências externas no financiamento dessas políticas. Em 1988, por exemplo, o tema central do Relatório sobre Desenvolvimento Mundial, do Banco Mundial foi a problemática das finanças públicas. Nesse documento, há a defesa de uma prática que viria a se tornar corrente no Governo Federal a partir de 1995, o superávit primário: “Para solucionar tais questões [depolíticas fiscaisinadequadas] équasesemprenecessáriauma combinação decortes dedespesa públicaeaumento da receita adicional, o quelibera recursos para as exportações epara o serviço da dívida" (1988, p.1). Além disso, tal documento definecom precisão o componentefundamental da nova estratégia, que ali échamado de "descentral ização da autoridade sobre a despesa e a receita", o que, mais tarde, se convencionará chamar, nos documentos dessas 
agências, dedesenvolvimento comunitário, esboçadosobre uma oposição entreas escal as local enacional: “... daí a criação degovernos locais quesejam receptivos aos desejos de seus cidadãos enão meros instrumentos dogoverno central." (1988, p.169).

Paraconsolidar essatransição, queduraum pouco mais deuma década, três iniciativas devem ser destacadas. No início dos anos 1980, foi criado o Programa deDesenvolvimento Rural do Nordeste, que gerou, em 1985, o Programa de Apoio ao Pequeno Produtor Rural do Nordeste (PAPP). ${ }^{4}$ O PAPP foi criado no dia 10 de abril de 1985 e tinha como preocupação "diminuir o grau depobreza" nazona rural (Sudene, 1990, p.2), aindase enquadrando, pelo menos até 1993, na categoria de programa de desenvolvimento rural. Depois, será redefinido no âmbito da nova estratégia centrada nas duas linhas mestras das políticas do BIRD hoje: desenvolvimento comunitário ealívio à pobreza.

Em 1991, foi criada, no Congresso Nacional, a Comissão Especial Mista sobre Desequilíbrio econômico inter-regional brasileiro, cujo objetivo foi fazer um balanço das ações do Estado no desenvol vimento regional epropor ações quesuperassem os "desequilíbrios" regionais. Essa comissão - que teve entre seus assessores técnicos o cearenseAntônio Rocha Magal hães, futuro coordenador do Projeto Áridas efoi presidida peloSe nador cearenseBeni Veras, que seria Ministro do Planejamento do Governo Itamar Franco ecomandaria a conclusão do Projeto Áridas, queabordare mos a seguir - produziu um relatório final cujas concl usões gerais apontavam para a necessi dade deumareorientação estratégica para o desenvolvimento regional. O relatório, entre outras coisas, anal isou as causas dos desequilíbrios regionais no Brasil e propôs, como saída, a superação das noções tradicionais de desenvolvimento regional, influenciadas ainda àquela época pela visão do GTDN, ea adoção de um novo modelo orientado pelas novas concepções de desenvol vimento que estavam em pleno amadurecimento equeatendi-

${ }^{4}$ Uma descrição do PAPP será feita mais adiante. am pelo nomede "desenvolvimento sustentável". O documento incorpora as críticas às políticas desenvol vimentistas, esboçando uma concepção de Estado e deregulação econômi ca de nítida ascendência neoli iberal, ao defender a aplicação de medidas como ajuste fiscal, abertura externa, desregulamentação da economia, desestatização, além da descentral ização eda “del egação decompetências" à sociedade (Brasil, 1993, p.32-33).

Em segui daà aprovação do relatório da Comissão Especial Mista sobre Desequilíbrio econômico inter-regional brasileiro, foi criado, em 1993, o Projeto Áridas, cuja missão era "elaborar" um novo modelo de desenvolvimento para o Nordeste. A definição que se segue está contida na contracapa do documento final desseProjeto:

O PROJETO ÁRIDAS é um esforço colaborativo dos Governos Federal, Estaduaise Entidades NãoGovernamentais, comprometidos com os objetivos do desenvolvimento sustentável no Nordeste. O Áridas conta com o apoio financei ro de Entidades Federais e dos Estados do Maranhão, Piauí, Ceará, Rio Grande do Norte, Paraíba, Pernambuco, Sergipe e Bahia, particularmente através de recursos do segmento de Estudos do Programa de A poi o ao Pequeno Produtor - PAPP, oriundo do financiamento do Banco Mundial. A execução do Áridas se dá no contexto de cooperação técnica e institucional entre o Instituto Interamericano de Cooperação para Agricultura - IICA e os Estados, no âmbito do PAPP (Brasil, 1994, p.2).

Para o Projeto Áridas, um dos pontos que distinguem o novo modelo (desenvol vimento sustentável) do anterior (desenvol vimentista) diz respeito à compreensão do desenvolvimento como um "processo global", um chavão usado pelos novos técnicos já plenamente integrados à nova estratégia, paradizer quea visão desenvolvimentista eraeconomicista eexclusivamentevoltada parao crescimento econômico. Especificamente, parao Projeto Áridas, o combateà pobreza ea participação da sociedade justificam a própria el aboração da nova estratégia, quepressupõeuma integração das ações políticas, dagestão edo controlesocial e exige uma adequação institucional ànova estraté gia, coerente coma "concepção que presideo ProjetoÁridas", cuja orientação sevinculaàs "novas tendências e concepções rel ativas ao Estado eàs 
suas relações coma sociedade", coma "redefinição dos papéis efunções das esferas públicas e privadas." (1974, p.174-175). É nesse contexto de redefinições estratégi cas que severifica uma adesão generalizada por parte dos governos estaduais nordestinosao novo paradigma de desenvol vimento, a partir de 1995, com a adoção de planos estaduais dedesenvolvimento sustentável queseguem o model o proposto pelo Projeto Áridas equetêm, no combate à pobreza, o objetivo justificador de toda a política dedesenvolvimento (Vieira, 2004).

\section{A ORIGEM DOS PROGRAMAS DE COMBATE À POBREZA NO NORDESTE}

Um caso significativo, que nos ajudará a entender elementos dessatransição, éo da Paraíba. O primeiro contrato de empréstimo entreo Governo da Paraíba e o Banco Mundial, que daria origem ao Projeto Cooperar, o 2860/BR (Brasil/BIRD, 1987), foi real izado durantea gestão do então governador da Paraíba, Tarcísio Burity (1987-1990), no val or deUS\$60 mil hões. O programa, elaborado fora dos cânones queiriam preval ecer nosanos 1990, nos três primeiros anos, dirigiu suas ações prioritariamente para o financiamento de redistribuição de terras, de irrigação pública e de crédito rural (Governo da Paraíba, 1989, p.5). É importante registrar que, apesar das pretensões inscritas no projeto original, nesses três anos de execução, nenhumafamíliafoi assentada por iniciativa do Programa, ao passo que, dos US\$ 60 milhões previstos, apenas US\$ 8,04 milhões foram executados em outros projetos (1989, p.9-11). Ainda em 1989, o contrato foi reformulado e foram abandonados definitivamente os programas dereforma agrária.

Projetos como esserepresentam os últimos sopros de vida da estratégia de desenvol vimento rural integrado financiada pelo Banco Mundial. Num país da importância política eeconômica do Brasil, na América Latina, ésal utar queas definições estratégi cas esperem a consoli dação de uma hegemonia ideológica, o quesó aconteceráapós a eleição queocorreem 1989, eo resultado consistiráno queo Financial Times chamou derevolução intelectual latino-americanacontra ochamado pensamento populista (Fiori, 1995, p.9).

Em 1993, o PAPP foi reformulado para se ajustar às novas concepções queestavam se delineando no âmbito do planejamento regi onal nordestino. Existiam vários problemas de execução do PAPP, como o "el evado sal do não desembolsado do financiamento, da ordem de US $\$ 500 \mathrm{mi}$ Ihões, e dos gastos com atividades-meio, como assistência técnica, pesquisa agropecuária eadministração do programa." (Soares, 1997, p.133). Não é possível compreender essas críticas sem levar em conta as novas estratégias. Os problemas observados no âmbito da administração dos recursos destinados aos projetos de desenvol vimento e as soluções de racional ização apontadas para superálosestão dentro do quadro das reorientações propostas e se ajustam às novas concepções de desenvol vimento regional queestavam em elaboração no interior dos estudos e proposições do Projeto Áridas.

Na descrição deSoares (1997):

Na reformulação foram cancelados US\$ 146,0 milhões do empréstimo origi nal do Banco Mundial, efoi substituída a estratégia de desenvol vimento rural integrado que o programa adotara atéentão. A nova estratégia baseia-se na comunidade rural, que passa a ter o direito de propor o projeto que consi dera prioritário, desde que seu custo não ultrapasse o val or de US $\$ 40.000,00$, e dereceber os recursos pleiteados afundo perdido. Em compensação, a comunidade assume a responsabilidade de implantá-lo e de mantêlo em operação. Os projetos do PAPP podemser implantados em qual quer área do estado, desdequehaja uma associação comunitária interessada, sendo possível instalar qual quer tipo de projeto, quer seja produtivo, de infra-estrutura ou social. No desenho do programa, coube ao governo federal contratar o financiamento junto ao Banco Mundial e assumir a responsabilidade de real izar o pa gamento do empréstimo. Ao Tesouro Nacional coube transferir aos estados executores do PAPP os recursos recebi dos do banco e os recursos da contrapartida nacional do programa, previstos desde a celebração do contrato no Orçamento Geral da União. Os estados não têm obrigação de ressarcir aUnião pel os recursos recebidos. Coma reformulação de 1993, o governo federal continuou como mutuário desses empréstimos, mas a contrapartida dos recursos naci onais passou a ser obri gação dos estados e das comunidades beneficiadas. (Soares, 1997, p.133) 
A implementação da nova estratégia teve duas avaliações. Uma delas, organizada pelo Governo Federal, desenvol vida por um Grupo de Trabalho Interministerial, queanalisou as experiências da Paraíba, dePernambuco, deAlagoas, do Rio Grande do Nortee do Ceará, concluiu quea proposta era problemática, por força da tendência à dispersão espacial das ações, à pulverização dos recursos e à possibilidade de uso político, o que col ocava em risco a sua sustentabilidade. A comissão chegou a propor quefossem feitas avaliações sobrea eficiência ea eficácia dos projetos do PAPP, nos casos de propostas de prorrogação dos contratos definanciamento. A segunda aval iação foi da responsabilidade dos técnicos do Banco Mundial eda Food and Agriculture Organization of the United Nations (FAO), e concluiu pela positividade da experiência, especial mentedevido ao aumento dos desembol sos do Banco. ${ }^{5} \mathrm{~A}$ ava liação do BIRD acabou por preval ecer sobrea do governo brasileiro. Essefato, por si só, érevelador sobrequal éa instância mai s rel evante para decidir sobre questões referentes ao desenvol vimento regi onal no Brasil. Senos, contratos anteriores, a União aparecia como tomadora do empréstimo, após 1993, ela passa a ser apenas fiadora. As decisões quanto à realização de novos contratos de empréstimos serão tomadas desde então pelo

\footnotetext{
${ }^{5}$ A avaliação do Banco Mundial sobre o desempenho do PAPP, no caso da na Paraíba, após a reformulação, é a seguinte: “O Estado de Paraí ba empreendeu dois programas de desenvolvimento rural financiados pelo Banco [Mundial] desde 1978, no âmbito do Polonordeste (Projeto Desenvolvimento Integrado Rural do Brejo Paraibano) e do NRDP [Northeast Rural Development Program/PAPP]. O desempenho da Paraíba sob os projetos financiados pelo banco antes da reformulação de 1993 do NRDP era, em geral, consistente com o desenvolvimento rural integrado do NRDP e com a experiência de outros estados do Nordeste. [...] Na vigência do NRDP reformulado, a Paraíba teve um desempenho al tamente positivo. Quase $40 \%$ de todo os subprojetos aprovados estavam sob a coordenação dos FUMACs [ConseIho Municipal de Apoio Comunitário], resultado dos esforços contínuos e efetivos da Unidade Técnica, combinada com uma tradição há muito existente no estado de ação associativa, além da reestruturação de ConseIhos deFUMAC ineficientes. A proximadamentetrês anos após a reformulação (fins de 1993 a fins de 1996), os desembol sos de empréstimo da Paraíba al cançaram US\$ 38,0 milhões, comparado aos US $\$ 21,4$ milhões durante o período inteiro de implementação do NRDP original (de 1985 a 1993) (...) Em uma base anual, a taxa de desembolsos mais que dobrou: foi de US\$4,4 milhões antes da reformulação para US $\$ 11,7$ mil lhão depois dela" (World Bank, 1997, p.8).
}

BIRD, após sol icitação dos governos estaduais ea análise da "adequação" da proposta.

Os estados da Bahia, do Ceará e de Sergipeapro-
vei taram a oportunidade e conseguiram, no iní-
cio do segundo semestre de 1995, autorização do
governo federal, por meio da Comissão deFinan-
ciamento Externo (COFIEX), para contratarem
novos financiamentos com o banco. A principal
alteração dos novos contratos é que o mutuario
do empréstimo passou a ser o governo estadual,
cabendo à União o aval do financiamento. Esses
contratos representam a continuidade dos atuais
PAPPs, embora, convenientemente, sua denomi-
nação tenhasido al terada para Programa deCom-
bate à Pobreza Rural. (Soares, 1997, p.133-134)

Não é por acaso, também, que todos os estados nordestinos, a partir de 1995, mesmo os governados por políticos considerados deesquerda, a exemplo deMiguel Arraes, em Pernambuco, cuidaram deelaborar "Planos deDesenvol vimento Sustentável", quediziam seguir as orientações do Projeto Áridas, e que também eram, não por acaso, as mesmas do Banco Mundial. É também em 1995, queo Governo Federal Iançao programa Comunidade Solidária, em clara consonânciacom a estratégia do Banco Mundial. Segundo o BIRD:

O nível de pobreza em certos segmentos da população, particularmenteno Nordeste, especialmente em suas áreas rurais, é uma preocupação elementar para a administração brasileira. Por causa daal ta incidência depobreza no Nordeste, esta região é uma prioridade nos programas de desenvol vimento. A base do esforço do Governo Federal para combater a pobreza e a fome é o programa ComunidadeSolidária, lançado no início de 1995 como uma ampla estrutura para coordenar programas e projeto de combate à pobreza rural e urbana e focal izado nos municípios onde a pobreza é muito severa. A implementação é descentral izada, com ênfase para a auto-ajuda comunitária e poder local, e concentrando em quatro temas principais: de senvolvimento rural, geração de emprego e renda, al imentação e nutrição, e serviços urbanos. (World Bank, 1997, p.11)

Os projetos decombateà pobreza dos estados nordestinos compõem um amplo programade combate à pobreza no Nordeste financiado pelo Banco Mundial, o Northeast Rural Poverty Alleviation Program. Detentor dos recursos para empréstimos a esses estados, o Banco Mundial determina não apenas o sentido estratégico das políticas dedesenvol vimento, comotambémaacei- 
tação e legi timação dos seus conceitos e anál ises sobrea realidadebrasileiraenordestina. O caso das políticas de combate à pobreza exprime mais um capítulo no turvo enredo do consenso gestado (pelo al to, como sempre) a respeito das alternativas no campo dos debates sobre desenvol vimento econômico e social. E isso não pode deixar de ser visto como perda de soberania a que está submetido o Estado brasileiro, visto agora, no caso aqui anal isado, sob o ângulo deum dos entes federativos prisioneiros de uma armadil ha que eles próprios ajudama manter, reproduzindo-a ao aceitarem as formas decontrole desuas orientações estratégicas.

O caso do Projeto Cooperar, formalmentede iniciativa do Governo da Paraíba, nos indica isso. Depois da década de 1980, a mudança na estratégia dedesenvolvimento regional não foi determinada nacional mente, isto é, sua origem não sesituou no âmbito do Estado nacional brasileiro. Um dado essencial quecorrobora essa afirmativa foi atransformação dos países querecebiam recursos do Banco Mundial emcampo deexperimentosarespeito das políticas mais adequadas de desenvolvimento ase remfinanciadas pelo Banco Mundial, quebuscava "model os" param serem aplicados em outros países. Nesse sentido, Antônio Rocha Magal hães, à épocaSecretário Executivo do Ministério do Plane jamento, descreveo processo demudança derumo no modelo de desenvol vimento aplicado ao Nordestea partir de 1993. Preocupada com a centralização naUnião- no quediz respeito àliberação de recursos de empréstimos do Banco Mundial, via PAPP, para os governos estaduais -, uma missão do BIRD propôs aorganização deumacomitiva para ir ao México com o objetivo de conhecer, in loco, a experiênciamexicanadedescentralização. Magalhães compartilhavadesseentendimento, defendendoque sefosse “às últimas conseqüências no processo de descentralização, afastando todo o complexo de agências governamentaisqueinviabilizavamo programa[PAPP]".

$$
\text { Magal hães descreveo model o mexicano }
$$

A comunidade reunida definia o que precisava fazer em primeiro lugar. Em seguida, elegia um presidente, um secretário e um tesoureiro que se encarregariam deimplementar o projeto, queera levado a um comi tê munici pal onde a prioridade era confirmada. Uma vez aprovado o projeto, a comunidade recebia $90 \%$ dos recursos, somava o seu trabal ho (equivalente aos 10\% restantes) e cui dava da implantação. Visitamos comunidades que estavam executando projetos deágua potável, escolas, melhorias urbanas. Em cada lugar, não apenas se via onde ecomo os recursos estavam sendo aplicados, mas se sentia o entusiasmo da população beneficiada.

[...] De volta ao Brasil, iniciamos de imediato o processo de transformação. [...] O novo model o do PAPP, implantado a partir de 1993, era totalmente descentralizado para as comunidades. A comunidade poderia tomar conhecimento do programa através deinformações divulgadas pelo governo ou através de qualquer outro meio. Ela deveria reunir-se, em democracia plena, para discutir os seus problemas e suas prioridades, indicando o que desejam em primeiro lugar. Nesse processo, geral mente se destacam lideranças natas. A comunidade também deveria formar uma associação, com presidente e uma diretoria, com poderes para assumir compromissos e receber e administrar recursos. A comunidade também indicaria representantes para um Conselho Municipal, que faria a priorização dos projetos a nível do município (2000, p.5-6).

A partir de 1995, o novo modelo ganha a forma que tem nos dias de hoje, evoluindo para uma quase completa autonomização frenteàs várias esferas de governo, embora mantendo ainda algum vínculo com os governos estaduais, através da contratação dos empréstimos edo controleque esses ai nda têm sobre as Unidades Técnicas que implementam os projetos nos municípios. No entanto, os governos nordestinos não têm nenhuma intervenção quanto à concepção e os chamados "delineamentos estratégicos", atuando muito mais como um organizador da estruturaadministrativa erepassador de recursos às comunidades.

Em 1997, aproveitando essa nova leva de financiamento, o Governo da Paraíba apresentaa proposta que viria a ser denominada de Projeto Cooperar.

\section{PROJETO COOPERAR: definições}

O Projeto de Combate à Pobreza Rural do Estado da Paraíba, ou Projeto Cooperar éresultado deum contrato deempréstimo efetivado em 16 defevereiro de 1998 entreo Governo da Paraíbae 
o Banco Mundial, tendo como fiador o Governo Federal (BIRD/Governo da Paraíba, 1998, p.2). Como já afirmamos, o Projeto Cooperar compõe um programa mais amplo de financiamento do Banco Mundial para o combateà pobreza no Nordeste, o NortheastRural Poverty Alleviation Program Rural Poverty Alleviation Project (Programa deAlívio da Pobreza Rural no Nordeste), queconta, desde1995, com projetos financiados para os estados da Bahia, CearáSergipe, Pernambuco, Rio Grande do NorteePiauí (World Bank, 1997). O val or total destinado ao financiamento desseProjetoédeUS\$ 80 milhões, sendo deUS $\$ 60$ mil hões a participação do Banco Mundial, US\$12,9 milhões a contrapartida do Governo Estadual eUS\$7,1 miI hões a partici pação das comuni dades beneficiadas. No caso das comunidades, a contrapartida podeser paga em dinheiro ou através da execução demão-de-obra eprodução demateriais (Governo da Paraíba, 2001, p.17). O primeiro contrato teve prazo de vigência decinco anos, iniciado em 1998 e concluído em 2003, adentrando, portanto, o mandato de um outro governador, o queestabeleceuma obrigação decontinuidade, independentementeda concordância do futuro governador. Em 2003, já com um novo governador (de oposição) eleito, Cássio Cunha Lima, o contrato foi renovado por um prazo de mais cinco anos.

O Projeto Cooperar financia pequenos empreendimentos, cujo principal objetivo é gerar emprego, renda einfra-estrutura para comunidades pobres, através do estabel ecimento de convê nios real izados diretamentecom associações eentidades representativas dessas comunidades. Além disso, financia projetos deel etrificação rural, construção de acessos, barragens, cisternas, aquisi ção de máquinas beneficiadoras de arroz e milho, processadores defrutas eleite, criação decaprinos, dessal inizadores, construção de passagens mol ha das, sistemas de abastecimento d'água completos esingelos, melhoria habitacional, creches, privadas earmazéns.

Paraa efetivação dos convênioseconcessão de recursos, o Banco Mundial considera fundamental o envolvimento das comunidades locais "na identificação, no planejamento, na execuçãoe na operação deseus investimentos", o que setraduz nos esforços decriar efortal ecer o capital social. ${ }^{6}$ Esses princípios estão ratificados num “Manual deOperações", uma exigência do BIRD para a assinatura do Contrato de Empréstimo (BIRD/ Governo da Paraíba, 1998, p.5), que defi niu regras eprocedimentos para a execução do projeto.

Assim, aparticipação das comunidades constitui o elemento decisivo paraaimplementação dos objetivos do Projeto Cooperar. São considerados "princípios estratégicos", nostermos do Manual de Operações do empréstimo, a "descentral ização, a participação comunitária, a transparência, al egitimi dade das demandas e a sustentabilidade dos investimentos conquistados pel os beneficiários." (Governo da Paraíba, 2001, p.13). O objetivo éenvolver as comunidades nos investimentos atéasua completa autonomização frente às organizações externas, ou seja, o Estado em suas diversas instâncias degoverno.

A execução do Projeto Cooperar se inicia coma sua divulgação para as comunidades. Estabelecido esse contato inicial eidentificado o interesse por parte da comuni dade, éiniciada a fase deassessoramento eapoio, que éfunção da UnidadeTécnica (corpo técni co indicado pelo Governo do Estado) queadmi nistra o Projeto na Paraíba.

A exigência mais importante para a apresentação de projetos équeas comunidades estejam organizadas emassociações comunitárias. Só assim, elas estarão aptas para a proposição de Subprojetos Comunitários "produtivos e sociais", destinados à geração deinfra-estrutura ede pequenosinvestimentos, queserão financiados quando aprovados por uma das três instâncias de decisão do Projeto Cooperar: oPrograma de Apoio Comunitário (PAC), quefinancia subprojetos encaminhados pelas associações diretamenteà UnidadeTécnica; o Fundo Municipal deApoio Comunitário (FUMAC), que financia subprojetos encaminhados pelas associações a um Conselho Municipal que administra o

6 “Habilidade das pessoas em conseguir benefícios mediante a sua participação em organizações comunitárias, inclusive associações" (World Bank, 1997, p.13). 
Fundo eque deveter, na sua composição, $80 \%$ de representantes do beneficiários e $20 \%$ de representantes do poder público (o FUMAC define a ordem de prioridades baseadas nos critérios de maior carência das respectivas comuni dades, eos projetos aprovadosnessa instânciasão encaminhados à UnidadeTécnica do Projeto Cooperar para a efetivação dos convênios); por fim, um Fundo Municipal de Apoio Comunitário Piloto (FUMAC-P), queé uma experiência-piloto de descentralização total na execução do Projeto Cooperar, ecujos Consel hos Municipais escol hidos têm autonomia para gerir os recursos e coordenar a execução dos subprojetos, a partir deum orçamento anual elaborado pelo próprio Consel ho Municipal a partir de um orçamento previamente aprovado para o FUMAC-P. O dado relevantedessa instância éque não existea necessi dade de aprovação daUnidade Técnica do Projeto Cooperar, cabendo a estaapenas orepassedos recursos definidos no subprojeto (Governo da Paraíba,2001, p.14-16).

Outro elemento central dessa estratégia éo financiamento deaçõesno âmbito do queéchamado de desenvolvimento institucional. O objetivo é desenvolver mecanismos que aperfeiçoem e consolidem as experiências de participação comunitária emesmo de "modernização ereforma do Estado", principalmenteatravés de "assistência técnica" de "consultorias". Sob o argumento de racional ização do uso dos recursos destinados a atender mais diretamenteàs populações pobres da Paraíba, o Projeto Cooperar objetivaestabel ecer uma articulação direta com a população rural, sem a mediação dos diversosníveis do Estado (municipal, estadual enacional). Por enquanto, essasinstâncias são apenas repassadoras dos recursos, sob a rigorosa supervisão do Banco Mundial. É o BIRD, através dos seus técnicos, quem determina os critérios de avaliação e conduz, de maneira autônoma, a partir das estratégias do banco, o desenvolvimento do Projeto Cooperar, com a completa anuência das admi nistrações estaduais. É o que demonstra a análise quefaremos a seguir das avaliações realizadas pelo Banco Mundial sobre oProjeto Cooperar.

\section{O DESEMPENHO DO PROJETO COOPERAR NAAVALIAÇÃO DO BANCO MUNDIAL}

O Banco Mundial procura exercer umrigoroso controlesobre os governos estaduais quantoà execução dos projetos dedesenvolvimento por ele financiados. No caso do Projeto Cooperar, essas exigências estão previstas nos seguintestermos:

...[o Governo da Paraíba deve] preparar, sob termos de referência satisfatórios ao Banco, efornecer, numa data 24 meses posterior à data efetiva ou quando os gastos da Conta de Empréstimo atingirem $50 \%$ do montante do Empréstimo, o que primeiro ocorrer, um relatório contendo os resultados das atividades de avaliação desempe nhadas [...] sobreo avanço conseguido na execução do Projeto durante o período precedente à data do relatório, e estabelecendo as medidas recomendadas para assegurar uma execução eficiente do mesmo e os mei os para atingir os seus objetivos durante o período seguinte a tal data (BIRD/Governo da Paraíba, 1998, p.9).

Diversasmissões do Banco Mundial visitaram com regularidadea Paraíba para "supervisionar" a execução do Projeto Cooperar diretamente nas comunidades. Masnão foi só isso. Comoconsta nos documentos produzidos pel os técni cos do Banco Mundial que registram essas visitas, intitulados "Ajuda Memória", essas missões se reuniram, também, comostécnicos do Projeto; em, pelo menos, duas ocasiões, foram real izadas reuniões com o Secretário de Planejamento e com o próprio Governador da Paraíba (Banco Mundial, 2002-2004, p.3). A partir de março de 2002, as visitas das missões tornaram-semais constantes. Nessas ocasiões, os técnicos do BIRD fizeram algumas "recomendações" sobreautilização dos recursos euma autorização para redirecionamento deum volumemaior derecursos para projetos de eletrificação rural, questão que, meses depois, será objeto dequestionamento pelo Banco.

Em maio de 2002, devido à existência de umvul toso vol umederecursos ainda não utilizados, foi feita uma recomendação para se promover, com a "máxima urgência", uma profunda reorientação na forma deexecução do Projeto Cooperar, sema qual não estava assegurada "a continuidade do apoio do Banco Mundial a esteProje- 
to" (Banco Mundial, 2002-2004, p.7). Essa "recomendação" foi feita diretamenteao governador da Paraíba na época, Roberto Paulino. O principal problema apontado, nessa oportuni dade, devia-se à utilização dos recursos, especificamenteno que diz respeito à baixali beração dos recursos viainstâncias do FUMAC, cujos projetos, como vimos, eram encaminhados pel as associações a um Consel ho Municipal e, após aprovados, deveriam ser encaminhados à UnidadeTécnica para execução. De acordo com o contrato de empréstimo BIRD/ Governo da Paraíba (1998, p.16), essetipo demodalidadedefinanciamento contava com recursos equival entes a $75 \%$ dos val ores provenientes do Banco Mundial, o que representava US $\$ 33,2 \mathrm{mi}$ Ihões, emai sos $20 \%$ da contrapartida do Governo daParaíbaecomunidades, o queacrescentavaal go em torno de US $\$ 6,6$ milhões. A té o fim de maio de2002, faltando um ano para a conclusão do re ferido Contrato de Empréstimo, apenas US\$13 milhões haviam sido li berados, restando US $\$ 27$ mil hões para serem utilizados. Por outrolado, até aquela data, quase todos os recursos (US\$ 22,78 milhões) destinados ao financiamento de projetos encaminhados pelas associações comunitárias diretamenteà UnidadeTécnica do Projeto Cooperar, queeraindicada pelo governador, haviamsido liberados, havendo ainda novos projetos queainda não tinhamfundos assegurados.

O problemaidentificado pelamissão doBancoMundial tema ver comasuaestratégia, queobje tivarestringir cadavez maisaingerência dos governos sobreas comunidades beneficiadas. Nareunião demaio de 2002, entre os técnicos do BIRD eo governador Roberto Paulino, foi acordada uma real ocação de US\$ 8 mil hões para a categoria PAC, visando a atender às novas liberações, ocasião em queostécnicos deixaram claro queessaseriaa"última" realocação queo BIRD autorizaria(Banco Mundial, 2002-2004, p.7), oqueindicaquehouveoutras real ocações, não identificadas nos registros, jáque, originalmente, acategoria PAC tinha fundos correspondentesa 17,64 milhões, sendo US\$14,7 do Banco Mundial (BIRD/Governo da Paraíba, 1998, p.16). Pelo acordo, só haverianovas liberaçõesviaFUMAC.
Pelas análises e recomendações da missão do BIRD, fica evidentequeos problemas identificados têm origem em práticas do Governo do Estado, quedesconsideraramas estratégias do banco, questão queéexplicitadapela exigênciafeitapeloBanco Mundial para que sejam respeitadas as "decisões tomadas pelos Consel hos em relação à ordem de prioridadedo atendimento das demandas comunitárias", bem como a "absoluta prioridade à liberação dos recursos do FUMAC". Além disso, o Banco Mundial passou a exigir a ampliação deConseIhosinstal ados eo estabelecimento deumorçamento indicativo para eles, além deuma "amplaeintensivadivulgação do Manual deOperação".

Entreas várias recomendações, uma chama especial atenção: o imediato encerramento da, até então, única experiência pi loto do FUMAC-P, instalado na cidadedeAraruna, quejá comprometera, atéaquela data, a quase total idade dos recursos a ele destinados, cerca de US\$700 mil (Banco Mundial, 2002-2004, p.10). Lembremos que o FUMAC-P éuma experiência quevisa a dar completaautonomia aos Consel hos Comunitários, sem anecessidadedeaprovação eacompanhamento da UnidadeTécnica. Cabe lembrar um detal heque, nesse caso, é de suma importância: Araruna éa cidade natal e reduto el eitoral do ex-governador JoséMaranhão, quegovernou a Paraíba de 1995 a abril de2002 edeixara o posto há pouco tempo, e em cujo governo foi assinado o contrato de empréstimo que deu origemà novaversão do Projeto Cooperar. Eis um bel o exemplo de conflito entre poder global e poder local.

Uma outrarecomendação chamaa atenção por aparecer nas aval iações posteriores feitas pelo Banco: a presença majoritária de projetos deeletrificação rural. Das 4.426 demandas cadastradas pela Unidade Técnica até maio de 2002, 1.814 (41\%) foram deel etrificação rural. Dos 1.826 projetos que tinham financiamento, 1.805 (99\%) eram deinfraestrutura e, desses, 65\% eram deel etrificação rural, enquanto os chamados subprojetos produtivos e sociais, que financiavam atividades econômicas ebenfeitorias comunitárias, representavam apenas $4,7 \%$ da demanda e $0,8 \%$ dos financia- 
mentos. A missão do banco viu, nessedescompasso entrea demanda (41\%) eo atendimento (65\%), um direcionamento orientado pelas prioridades estabelecidasnão pel as comuni dades, mas pelo Governo do Estado (Banco Mundial , 2002-2004, p.4).

Nasaval iações seguintes, realizadas emagosto, setembro e novembro de 2002, as missões do BIRD constataram queas recomendações feitas em mai o estavam sendo cumpridas, tendo sido ampliado o número de convênios via FUMAC, com a ampliação do número de experiências de autonomia gerencial efinanceira via FUMAC-P, quepassou de um para 17, com 18subprojetos com financiamentos liberados. A experiência deArarunajá haviasido cancel ada em maio. Além disso, constatou-seaampliação do financiamento desubprojetos produtivosesociais, queobtiveram 153 aprovações, mais de $50 \%$ do total de projetos (299).

Emjunho de2004, jáno novo governo eleito em 2002, foi real izada umasupervisão queteve como objetivo aval iar o desempenho geral do Projeto Cooperar, já queo contrato deempréstimo se encerrara, eo novo governo pleiteava umarenovação. Os números dessa aval iação são os seguintes: 3.200 subprojetos financiados, $27 \%$ além da meta estabel ecidaem 1998, beneficiando 113 mil famílias, nos 222 municípios do estado, através de2.600 associações e 220 Consel hos do FUMAC. Dos 3.200 subprojetos, 1.400 foram de eletrificação rural , 1.180 de abastecimento deágua (incluídas 224 cisternas domiciliares), 226 mel horias sanitá rias (Banco Mundial, 2002-2004, p.1-6). Mesmo comos problemas verificados (ecorrigidos), os técnicos do BIRD consideraram que a execução da estratégia não fora comprometida. O contrato foi renovado por mais 5 anos.

\section{CONCLUSÃO}

Nosúltimosanos, a categoria "pobreza" ganhou status decentral idadeno discurso das agências internacionais. Isso pode ser observado nos relatórios anuais sobre desenvolvimento produzidos pelo Banco Mundial, e se concretiza com a abertura de créditos para países "em desenvolvimento", destinados a financiar políticas decomba teà pobreza. Como já chamamos a atenção, foi o Relatório sobreo desenvolvimento mundial, de1990 (Banco Mundial, 1990), que estabeleceu o marco dessa nova estratégia. Nesse senti do, 1990 éo anobasedeumaação quedevedurar 25 anosedeonde separteparaseal cançar os "Objetivos do milênio", traçados pelo ONU. Entreesses objetivos, o combateà pobrezafigura em primeirolugar. ${ }^{7}$ Tanto queas metas da ONU representam, segundo o representante do PNUD e coordenador da ONU no Brasil, Carlos Lopes, um inédito "consenso internacional perantealuta contraa pobreza" (PNUD, 2006).

Nesteartigo, analisamoso Projeto Cooperar, quecompõeuma política decombateà pobreza formal mentedainiciativa de um estado nordestino, a Paraíba. Tal Projeto é um exemplar de um amplo programadecombateà pobrezano Nordeste, financiado peloBanco Mundial, o NortheastRural Poverty Alleviation Program - Programa deAlívio da Pobre za Rural no Nordeste. Detentor dos recursos para empréstimosa esses estados, o Banco Mundial determinanão apenas o sentido estratégico das políticas de desenvolvimento, como a aceitação e a legitimação dos seus conceitos e análises sobre a realidadebrasileiraenordestina. O caso das políticas decombateà pobreza exprimemais um capítuI o no turvo enredo do consenso gestado (pelo al to, como sempre) a respeito das alternativas no campo dos debates sobre desenvolvimento econômico e social. E isso não pode deixar de ser visto como perda desoberania do Estado brasileiro, visto agora, no caso aqui analisado, sob o ângulo deum dos entesfederativos prisioner ros deumaarmadilhaque eles próprios (os estados nordestinos) ajudam a manter, reproduzindo-a ao aceitaremas formas de control eeorientações estratégicas deagência definanciamento externas.

Como vimos, a partir de 1995, o novo model o ganha a forma quetem nos dias dehoje, evoluindo para uma quase completa autonomização

\footnotetext{
7 “Meta 1 - Reduzir pela metade, entre 1990 e 2015, a proporção da população com renda inferior a um dólar PPC por dia" (PNUD, 2006).
} 
frenteàs várias esferas de governo, mantendo aindaal gum vínculo com os governos estaduais, através da contratação dos empréstimos edo controle que eles ainda têm sobre as Unidades Técnicas queimplementam os projetos nos municípios. No entanto, como demonstramos no caso do Projeto Cooperar, o governo parai bano não tem intervenção al guma quanto à concepção e os chamados delineamentos estratégicos, atuando muito mais como um organizador da estrutura administrativa e repassador de recursos às comunidades. Os dois casos aqui apresentados deixam claras essas limitações políticas econstituem evidências nítidas da interferência do Banco Mundial emassuntosinternos do governo parai bano. O primeiro diz respeitoà prioridadedada pelo Governo da Paraíba à aprovação eliberação de recursos para projetos de eletrificação rural. Ora, parecenos óbvio que qual quer iniciativaquedeseje promover o "desenvolvimento comunitário", nos seus vários níveis, deve prover essas comunidades de um bem essencial, que é o acesso à energia elétrica, o que Ihes permitiria dar "sustentabilidade" a seus empreendimentos, bem como obter umamel hor qua lidade de vida. Pois bem: como vimos, o Banco Mundial vetou essa prioridade, defendendo uma mai or diversificação das ações, para atender às reivindicações das comuni dades e não à estratégia do Governo do Estado. Trata-se, diria um liberal, deuma racional ização do uso dos recursos escassos, diante das ilimitadas necessidades dessas comuni dades. Como não há recursos para tudo, queas comunidades façam suas próprias escol has. O nítido direcionamento estabel ecido pel o governo parai bano na aprovação eliberação derecursos para projetos de el etrificação rural constituiu interferênciaindevida, eo Banco Mundial forçou a suspensão do procedimento, com a devida anuência do Governo da Paraíba.

Além disso, parececlaroque, comessaação, o Banco Mundial procura manter coerência com as referências teóricas, políticas e ideológicas estabelecidas. A atitude descrita acima valida a pedra detoqueconceitual dos elaboradores dessa estratégia: o capital social, que, na definição de
Putnan, um pouco mais ampla quea do BIRD, diz respeito a "características da organização social, como confiança, normas esistemas, quecontribuam para aumentar a eficiência da sociedade, facilitando as ações coordenadas" (Putnam, 1996, p.177). Naretórica, o queo Banco Mundial provavelmentedesejaéuma mudança cultural nointerior dessas comunidades, que lhes permita uma autonomização frenteao Estado eaos grupos políticos locais, em busca da sustentabilidade do desenvol vimento comunitário, umaculturacujo ponto departida sejauma espécie deacumulação primitiva decapital social, queo Banco Mundial procura prover. Ou seja, mais do que infra-estrutura e financiamento para pequenos empreendimentos, são instituições enormas quese procuram estabelecer, a partir das quais se al meja promover uma nova organização social, culturalmentemais eficiente, mais produtiva eempreendedora, emsubstituição a uma tradição reconhecidamente patrimonialistaedominada pelos grupos políticos Iocais e pelo Estado mantenedor dessas estruturas, o que limita a iniciativa dos indivíduos. Em suma, citando um outro ícone desse debate, Amartya Sen, um dos el ementos centrais para se al cançar o desenvolvimento tem como fundamento a expansão das li berdades reais deescol ha. São os val ores e os costumes sociais de uma determinada sociedadeque "também respondem pela presença ou ausência de corrupção e pelo papel da confiança nas relações econômicas, sociai sou políticas. O exercício da liberdade é mediado por val ores que, por sua vez, são influenciados por discussões públicas einterações sociais, quesão, elas próprias, influenciadas pelas liberdades de participação." (Sen, 2000, p.24). Emsíntese, a razão do desenvolvimento é, em tese, além de promover a mel horia das condições de vida dosindivíduos (saúde, alimentação, educação, acesso a recursos como água, terra, energia elétrica), ampliar as capaci dades desses indi víduos na esfera de suas relações (nafamília, na comuni dade, no trabalho) e dos seus papéis sociais (como mulher, trabal hador, etc.). São essas capacidades que ge ram oportunidades eque, por sua vez, definem o 
destino desses indivíduos.

James Wolfensohn, presidente do Banco Mundial entre 1995 e2005, procurou definir com mais precisão o papel da participação social no desenvolvimento:

Participação real mente é importante - não ape nas como instrumento para melhorar a eficácia do desenvolvimento como temos apreendido a partir de estudos recentes, mas também como o fator-chave para garantir a sustentabilidade e al avancagem a longo prazo. Nunca devemos nos esquecer quecabe ao governo eaos povos decidirem quais devem ser as prioridades. Nunca devemos nos esquecer que não podemos e não de vemos impor o desenvol vimento "por decreto', vindo de cima ou vindo de fora. (Wolfensohn, apud Garrison, 2000, p.59)

Apesar da referência ao governo, as ações queo Banco Mundial procura promover cadavez maislimitamaautonomia desses governos (obviamente, não setrata de todos os governos) para criar eimplementar suas próprias estratégias. Já que essas estratégias, emoutrostempos, eram, por princípio, produto deestudos eanál ises que precediam uma ação gl obal por partedo Estado, o desenvolvimento comunitário, ao mesmo tempo em que estimula a organização e participação social das comunidades pobres, fragmenta a ação do Estado noterritório. Configura-se, na prática, uma oposição entreos objetivos das comunidades, necessariamentelocalizados, eos do Estado, em geral articulados dentro do território.

Três questões podem ser interpostas para finalizar essa discussão. A primeira é se a al avancagem dessa nova cul tura podeser realizada apenas pela disponibilização de recursos eforça política externa às comunidades locais. A segunda éseo Estado-nação se tornou dispensável nos papéis tradicionais de organizar economicamente esocial mente o território. E, por fim, mesmo consi derando quea opção do Banco Mundial por priorizar a organização das comunidades locais possa parecer mais democrática, cabea elenão apenasfazer essa escol ha, como implementála.

(Recebido para publicação em dezembro de 2006) (Aceito em janeiro de 2008)

\section{REFERÊNCIAS}

ANDRADE, Manuel Correia de. Espaço, polarização e desenvolvimento. São Paulo: Ed. Brasiliense, 1973.

ARAÚJO, Tânia Bacelar. Nordeste, Nordestes. Que Nordeste? In: AFFONSO, Rui de Britto Álvares; SILVA, Pedro Luiz Barros (Org.) Desigualdades regionais e desenvolvimento. São Paulo: FUNDAP/Editora UNESP, 1995

BANCO MUNDIAL. Relatório sobre o desenvolvimento mundial 1988. Washington, D.C.: Banco Mundial, 1988.

. Relatório sobre o desenvolvimento mundial: a pobreza. Washington, D.C.: Banco Mundial, 1990.

Informe sobre el desarrolo mundial 1992: desarrolo y médio ambiente. Washington: Banco Mundial. 1992

Ajuda memória. Supervisões do Banco Mundial ao Projeto de Combate à Pobreza Rural - PCPR PB (Cooperar). João Pessoa, maio de 2002 a junho de 2004.

- O Banco Mundial no Brasil: uma parceria de resultados, 2004. Disponível em: www.obancomundial .org/index.php/content/ view_document/1512.html Acesso em: 20 jun. 2005.

BIRD/GOVERNO DA PARAÍBA. Contrato de empréstimo no4251/BR entre o Banco Interamericano para a Reconstrução e o Desenvolvimento e o Estado da Paraíba. João Pessoa, fev., 1998.

BRASIL. Congresso Nacional. Comissão Especial Mista Para Estudo do Desequilíbrio Econômico Inter-regional Brasileiro. Desequilíbrio econômico inter-regional brasiIeiro. Relatório final. Brasília: Senado Federal, 1993. 3v.

Ministério do Planejamento. Projeto Áridas. Nordeste: uma estratégia de desenvolvimento sustentável. Brasília: 1994. 216p.

BRASIL/BIRD. Contrato de empréstimo n20206/BR entre a República Federativa do Brasil e o Banco Interamericano para a Reconstrução e o Desenvolvimento. Brasília: jul., 1987.

BRESSAN, Delmar. Gestão racional da natureza. São Paulo: Hucitec, 1996.

CARVALHO, Inaiá Maria M. de. O Nordeste e o regime autoritário. São Paulo: Hucitec, 1987.

CHESNAIS, François. A mundialização do capital. São Paulo: Xamã, 1996.

DA SILVA. Severino Bezerra. Perímetro irrigado do Curaçá: um espaço para o capital. Um estudo sobre a intervenção do Estado nos espaços agrários nordestinos. 1989. 39f. Monografia (Especialização em História) - Departamento de História, Universidade Federal da Paraíba, João Pessoa, 1989.

ESPLAR. Banco Mundial e BID aportam mais de 2 biIhões no Nordeste. Dezembro de 1989. Disponível em: www.esplar.org.br/noticias/dezembro/2004/09.htm> Acesso em: 20 jun., 2005.

FIORI, Jose Luis. O vôo da coruja: para reler e desenvolvimento brasileiro. Rio de Janeiro: EdUERJ, 1994

Em busca do dissenso perdido. São Paulo: INsight Editorial, 1995.

GARRISON, John W. Do confronto à colaboração: relações entre a sociedade civil, o Governo e o Banco Mundial no Brasil. Brasília: 2000. Disponível em: w w w. obancomundial.org/content/ _downloadblob.php?cod_blob=718 Acesso: 13 ago., 2005 GONÇALVES NETO, Wenceslau. Estado e agricultura no 
Brasil: política agrícola e modernização econômica brasileira 1960-1980. São Paulo: Hucitec, 1997.

GOVERNO DA PARAÍBA. Proposta de reprogramação do Contrato 2860/BR. João Pessoa: dez., 1989.

Secretaria de Planejamento. Plano de desenvolvimento sustentável da Paraíba. João Pessoa: 1995. 41p.

Manual de operações: Projeto de Combate à Pobreză Rural-PCPR (Cooperar). João Pessoa: dez., 2001.

MAGALHÃES, Antonio Rocha. Desenvolvimento comunitário e combate à pobreza no Nordeste. Brasília: 2000. Disponível em: www.bird.org.br/content/ downloadblob.php? cod_blob=283 Acesso em: 05 fev., 2005.

MEADOWS, Denis et al. Os limites do crescimento. São Paulo: Perspectiva, 1978. p.97-110.

PERROUX, François. A economia do século XX. 2.ed. Lisboa: Livraria Morais, 1967

O conceito de pól o de crescimento. In: FAISSOL, Speridião. Urbanização e regionalização: relações com o desenvolvimento econômico. Rio de Janeiro: IBGE, 1974.

PNUD. Objetivos de desenvolvimento do milênio. 1996. Disponível em: www.pnud.org.br/odm/index.php Acesso: 18 set. 2005

PUTNAM, Robert D. Comunidade e democracia. A experiência da Itália moderna. Rio de Janeiro: Ed. Fundação Getúlio Vargas, 1996.
SEN, Amartya. Desenvolvimento como liberdade. São PauIo: Companhia da Letras. 2000

SOARES, Ricardo Pereira. Avaliação do financiamento do Banco mundial ao programa de Apoio ao pequeno produtor rural do nordeste (PAPP). Planejamento e Políticas Públicas, Brasília, n.15, p.131-162, jun., 1997

SUDENE. APCR: a estratégia operacional do PAPP. Recife, jul., 1990. Mimeografado

VALLE, Raul Octávio A. do. Um enfoque do desenvolvimento rural integrado: o Polonordeste. João Pessoa: Ed. UFPB, 1977.

VIEIRA, Flávio L. R. Sudene e desenvolvimento sustentável: planejamento regional na década neol iberal. J oão Pessoa: Ed. UFPB, 2004.

Globalização, nordeste e planejamento regional. 1994. 157f. Dissertação (Mestrado em Sociologia) Programa de Pós-graduacãoo em Sociologia da Universidade Federal da Paraíba. João Pessoa: 1994.

WORLD BANK. Northeast Rural Poverty Alleviation Program Rural Poverty Alleviation Project - Paraiba (Report no16757-BR). Disponível em: www.bancomundial.org.br/ content/downloadblob.php?cod_blob=184 Acesso em: 16 jun., 2005. 


\section{O BANCO MUNDIAL E O COMBATE À POBREZA NO NORDESTE: o caso da Paraíba}

Flávio Lúcio Rodrigues Vieira

Neste artigo, é estudada a participação do Banco Mundial no financiamento do Projeto Cooperar, um plano de combate à pobreza, em execução pelo Governo da Paraíba desde 1997. Na primeira parte, enfocamos a atuação do BIRD, analisando as mudanças ocorridas nas estratégias aplicadas no Nordeste e a crescente participação dessa instituição internacional no financiamento de políticas de desenvolvimento voltadas para a região. Procuramos enfatizar as mudanças ocorridas na estratégia do Banco Mundial voltados ao financiamento de projetos orientados pela idéia de desenvolvimento rural, experiências que foram fundamentais para o aperfeiçoamento dos mecanismos de atuação do BIRD no Brasil e que constituem elementos antecedentes da estratégia de combate à pobreza no Nordeste durante a década de 1990. Na segunda parte, a análise é orientada para o Projeto Cooperar, exemplar de política de combate à minadas suas origens, sua estratégia e o nível de interferência do Banco Mundi- in the implementation of th
al na implementação da estratégia de development strategy are examined. ○ desenvolvimento.

Palavras-Chave: pobreza, desenvolvimen- Paraíba, Northeast. to, Estado, Paraíba, Nordeste.

\section{THE WORLD BANK AND THE COMBAT TO POVERTY IN THE NORTHEAST: the \\ Paraíba case}

Flávio Lúcio Rodrigues Vieira

In this article, the participation of he World Bank in the financing of the Cooperar Plan is studied. Cooperar is a plan to combat poverty, in execution by the Paraíba Government since 1997. In the first part, we focused on the BIRD performance, analyzing the changes Northeast and to growing participation of that international institution in the

nancing of development politics for

the area. We tried to emphasize the changes occurred in World Bank strategy guided by the idea of rural development, experiences that were fundamental for the improvement of the mechanisms of BIRD performance in Brazil and that constitute precedent elements of the fondamentales pour le perfectionnement rategy to combat poverty in the des mécanismes d'action de la BIRD au Northeast during the decade of 1990. In Brésil et sont des éléments antérieurs à he second part, the analysis is guided la stratégie de combat contre la pauvreté o the Cooperar Project, example of policy dans le Nord-est, au cours des années o combat poverty in the Northeast, 1990. Dans la deuxième partie, on frait when its origins, its strategy and the l'analyse du Projet Cooperar lui-même, evel of interference of the World Bank modèle de politique de combat contre ses origines, sa stratégie et le étudiant ses origines, sa stratégie et le niveau d'inteférence de la Banque

KFYwORD: Poverty, development, State, Mondiale pour la mise en place de la stratégie de développement.

Mots-CLÉs: pauvreté, développement, Etat, Paraíba, Nord-Est. 